Article

\title{
Critical Review of Scintillating Crystals for Neutron Detection
}

\author{
Michał J. Cieślak ${ }^{1} * \mathbb{D}$, Kelum A. A. Gamage ${ }^{2}(\mathbb{D})$ and Robert Glover ${ }^{3}$ \\ 1 Engineering Department, Lancaster University, Lancaster LA1 4YW, UK \\ 2 School of Engineering, University of Glasgow, Glasgow G12 8QQ, UK; kelum.gamage@glasgow.ac.uk \\ 3 Radiometric Systems Group, Sellafield Ltd., Seascale CA20 1PG, UK; robert.glover@sellafieldsites.com \\ * Correspondence: m.cieslak@lancaster.ac.uk
}

Received: 29 July 2019; Accepted: 8 September 2019; Published: 13 September 2019

check for updates

\begin{abstract}
There exists an ongoing need to develop and improve methods of detecting radioactive materials. As each radioactive isotope leaves a unique mark in a form of the particles it emits, new materials capable of detecting and measuring these particles are constantly sought. Neutrons and their detectors play a significant role in areas such as nuclear power generation, nuclear decommissioning and decontamination, border security, nuclear proliferation and nuclear medicine. Owing to the complexity of their detection, as well as scarcity of ${ }^{3} \mathrm{He}$, which has historically been the preferred choice for neutron detection in many application fields, new sensitive materials are sought. Organic and inorganic scintillating crystals have been recognised as particularly good alternatives, and as such systems that utilise them are increasingly common. As they allow investigation of the neutron energy spectra, greater information about the radioactive source can be inferred. Therefore, in this article, an extensive review of scintillating crystals used for neutron detection is presented. By describing the history of scintillating crystals and discussing changes that occurred in their use and development of methods for radiation detection, the authors present a comprehensive overview of the current situation. Supported by a practical example, possible future directions of the research area are also presented.
\end{abstract}

Keywords: scintillators; scintillating crystals; neutron detectors; gamma detectors; ${ }^{3} \mathrm{He}$ deficit

\section{Introduction}

Radiation detection plays an important role in many application fields such as nuclear medicine, power generation, border control and nuclear decommissioning. Regardless of the application field, radiation detectors are primarily deployed to ensure safety of the personnel either working with, or in the close proximity, of the radioactive substances [1]. Further, they are essential to border and security control, where they are used to prevent illegal transportation of dangerous items [2]. Irrespective of the way they are used, a sensitive material is required that interacts directly with the targeted or expected radiation field. A large number of these devices use scintillating materials as radiation sensitive medium.

The history of the scintillating materials used for radiation detection goes back to the work by Röntgen and his famous discovery of X-rays [3]. In his experiment, Röntgen placed barium platinocyanide plates in the close vicinity of vacuum tubes with $\mathrm{CaWO}_{4}$ powder, which was previously discovered by Crookes [4]. He discovered that materials, such as lead, are opaque to the X-rays, whereas other materials, such as aluminium, are transparent. Most famously, he discovered that X-rays can be used to image bones of a human body, because calcium absorbs the X-rays owing to its relatively high atomic number, whereas tissues in other body parts are built of elements characterised with lower density. As such, they are more transparent to this type of radiation. 
This discovery was embraced by a large scientific community as it allowed them to investigate previously unknown properties of materials. One of the materials investigated was crystal, as described by Friedrich et al., where they discovered X-ray diffraction within the crystal [5]. Around the same time, the structure of crystals was described based on the X-ray diffraction [6]. What became apparent as a result of these experiments was that crystals are capable of scintillating when exposed to X-rays, and thus their interactions in crystals could be observed.

Initially, the fluorescence produced by scintillators was observed by the naked eye, which made it difficult to conduct a suitable investigation. The requirement for a suitable photodetector resulted in the discovery of a photomultiplier tube (PMT). There exists some controversy related to the discovery of PMT, but the first electrostatic PMT (similar to the devices still produced and used today) was presented in 1936 by Zworykin et al. [7]. Nonetheless, the discovery of PMTs opened up a new chapter in the history of scintillating crystals, as it made the investigation of the new materials easier and enabled new properties to be found.

In this article, a review of the available crystal scintillators for radiation detection, with particular focus placed on neutron detection, is presented. In the following sections, an overview of the types of crystals used for radiation detection with regard to their chemical structure and particle sensitivity is presented. Further, both organic and inorganic crystals used for neutron detection are discussed in detail, as well as their growing importance given the scarcity of ${ }^{3} \mathrm{He}$ and limitations of other detection methods. The discussion is supported through numerous examples from the literature, as well as a practical example of a response of an organic crystal to the mixed neutron/gamma $(\mathrm{n} / \mathrm{g})$ field provided by ${ }^{252} \mathrm{Cf}$. The article is concluded with a discussion about possible future directions and expectations of where crystals may be used to further support neutron detection capabilities.

\section{Scintillating Crystals Used in Radiation Detection Applications}

Regardless of the chemical type of a scintillating material, the process of extracting information from an interaction occurring within a scintillator is largely the same. When energetic particles enter the scintillator, they cause ionisation, either directly or indirectly. In the case of charged particles, e.g., protons, electrons and alpha particles, they ionise the scintillator directly. Quanta and particles without charge, such as photons and neutrons, must first transfer their energy to ionising particles within the medium. For instance, photons can liberate electrons and neutrons undergo nuclear interactions resulting in a release of charged particles (e.g., $\alpha$, proton). All the charged particles produced can then ionise the material raising atoms and molecules to excited states.

These then emit photons of visible light as they de-excite, which can be later transformed into photoelectrons through a photocathode of a photodetector such as PMT. PMTs multiply the weak signal of photoelectrons and form an electrical pulse, which carries important information about the incident radiation [8]. These can be easily detected through a combination of analogue and digital electronics.

Characteristics of pulses observed on the outputs of a photodetector, such as their length, height, rise time, decay time, are measured and used to infer the origin of the interaction within the scintillator. These characteristics differ between scintillators and incident particles, owing to distinctive interactions that govern the scintillation process. The differences can be observed and analysed, enabling the information on incident particles to be inferred. The most basic distinction related to crystals is between organic and inorganic crystals.

\subsection{Operation Principle of Inorganic Crystals}

One of the most frequently used crystals in radiation detection is NaI. This single crystal of alkali halide is characterised by very good spectrometric response to gamma-rays. Pure NaI crystal is an example of an insulating material. As such, its energy band structure consists of a valence band, which is normally full, and a conduction band, which is normally empty. The two are separated by gap band, which is also known as forbidden gap or energy gap [8,9]. When exposed to ionising radiation, the electrons from the valence band can be excited and move onto the conduction band. A hole in the 
valence band is filled when an electron returns from the conduction band. This process is accompanied by the release of a photon. However, the width of the energy gap means that the energy of the photon released is too high to be in the visible region, resulting in low light yield in the pure NaI crystal [9].

In order to alleviate this problem, impurities are introduced to inorganic crystals. These are called "activators" and are introduced to increase the likelihood of emitting photons that can be detected through conventional photodetectors. When an electron is returning to the valence band in an insulating material such as pure NaI, a photon may be emitted. However, due to the width of the energy band, it may be self-absorbed. Therefore, the energy band structure of the crystal matrix is changed when an activator is added. The activator introduces states within the energy gap of the pure crystal matrix. Thus, photons, which can be easily detected through conventional methods, can be emitted.

One of the most common activators is Tl. As an example, this activator alters the maximum emission wavelength from $303 \mathrm{~nm}$ in pure $\mathrm{NaI}$ to $450 \mathrm{~nm}$ in thallium doped NaI crystal, and notation $\mathrm{NaI}(\mathrm{Tl})$ is used [8]. Generally, activators create new regions within the crystalline structure of a scintillator, which are sometimes referred to as "luminescence centres" or "emission centres". These enable the scintillators emitted wavelengths to be more closely matched with the sensitivity regions of the PMTs.

Depending on the application different properties of the inorganic crystals may be sought. However, there exists a basic set of requirements that is desirable across many application fields which includes a fast response, high light yield, high density and high atomic number [10]. Excellent gamma-ray sensitivity and energy resolution should naturally lie above the aforementioned characteristics. A material meeting all of these criteria does not exist. For instance, $\mathrm{NaI}(\mathrm{Tl})$ and $\mathrm{CsI}(\mathrm{Tl})$ are characterised by the high light yield, but relatively slow response time. In contrast, pure CsI crystal exhibits very fast response but low light yield in the room temperature range. One of the inorganic crystals was utilised in varied application areas because of its unique combination of the specified characteristics is $\mathrm{Lu}_{2} \mathrm{SiO}_{5}(\mathrm{Ce})$ (LSO) [11]. As such, it was successfully exploited, together with its modified version containing yttrium, e.g., $\mathrm{Lu}_{1.8} \mathrm{Y}_{0.2} \mathrm{SiO}_{5}(\mathrm{Ce})$ (LYSO), in, e.g., nuclear medicine for positron-emission tomography (PET) applications.

Inorganic crystals were primarily developed for application in gamma-ray detection and characterisation applications, due to their suitability in areas requiring excellent energy resolution. However, there have been numerous inorganic crystals developed, which are directly aimed at low-energy neutron detection. This is possibly because the crystals contain a high neutron cross-section material, such as Li [9].

\subsection{Inorganic Crystals Capable of Neutron Detection}

Owing to their high cross-section for low-energy neutron capture, the most commonly used isotopes are ${ }^{10} \mathrm{~B},{ }^{6} \mathrm{Li}$ and ${ }^{3} \mathrm{He}$. The most common nuclear reaction with ${ }^{3} \mathrm{He}$, used for neutron detection, is defined in Equation (1). It is accompanied by the release of $0.764 \mathrm{MeV}$ of kinetic energy, and a cross-section of 5330 barns, for thermal neutrons [9]. Fast neutron detectors based on ${ }^{3} \mathrm{He}$ have also been implemented, where appropriate moderating material is added to thermalise the fast neutrons [12]. However, scarcity of ${ }^{3} \mathrm{He}$, caused by the decline in tritium production for nuclear weapons maintenance, requires that other alternatives be sought [13].

$$
{ }_{2}^{3} \mathrm{He}+{ }_{0}^{1} \mathrm{n} \longrightarrow{ }_{1}^{3} \mathrm{H}+{ }_{1}^{1} \mathrm{p}+0.764 \mathrm{MeV}
$$

One of the proposed alternatives are organic scintillation detectors utilising "elastic scattering" of neutrons with light atoms, such as hydrogen $[14,15]$. When considered as an alternative for ${ }^{3} \mathrm{He}$ detectors, organic scintillation detectors exhibit gamma-ray sensitivity, which requires particles to be separated. However, detection systems exploiting both scattering and particle separation techniques 
(will be discussed in the following section) have shown promising performance with regard to source localisation and particle identification [16].

\subsection{Detectors Utilising ${ }^{6}$ Li Neutron Reaction}

Out of the remaining two isotopes, ${ }^{6} \mathrm{Li}$ has been the most widely adapted in inorganic crystals. One of the examples of a scintillating crystal capable of neutron detection, which contains $\mathrm{Li}$, is another alkali halide- $-\mathrm{LiI}(\mathrm{Eu})$. Detectors containing Li represent a group of potential candidates for detection of low-energy neutrons owing to the ${ }^{6} \mathrm{Li}(\mathrm{n}, \alpha)$ reaction, as defined in Equation (2).

$$
{ }_{3}^{6} \mathrm{Li}+{ }_{0}^{1} \mathrm{n} \longrightarrow{ }_{1}^{3} \mathrm{H}+{ }_{2}^{4} \alpha+4.78 \mathrm{MeV}
$$

When a scintillator is sensitive to both neutrons and gamma-ray photons, it is necessary to separate the two particle types. This phenomenon is often referred to as pulse shape discrimination (PSD) and is very common in the domain of organic scintillators. The $\alpha$ particle resulting from neutron's interaction with ${ }^{6} \mathrm{Li}$ can be detected and easily classified through the PSD methods [17].

A relatively recent study investigating the doping of the pure $\mathrm{LiI}$ crystal with $\mathrm{Eu}^{2+}$ shows that appropriate doping level, as well as heat treatment, may hold an answer to the light yield problem when used for neutron detection. It should be noted that the heat-treated $\mathrm{LiI}: \mathrm{Eu}^{2+}$ scintillator examined by Boatner et al. [18] also shows excellent spectral response to gamma-rays from ${ }^{137} \mathrm{Cs}$ calibration source.

Another detector utilising the high thermal neutron cross-section of ${ }^{6} \mathrm{Li}$ isotope is $\mathrm{Ce}^{3+}$-doped $\mathrm{LiCaAlF}_{6}$ inorganic crystal. When experimentally tested, this detector's performance was compared to that of a commercially available Li-glass scintillator [19]. Samples of two different sizes of $\mathrm{LiCaAlF}_{6}$ were manufactured and tested in regard to the light yield, $\mathrm{n} / \mathrm{g}$ separation capabilities and neutron detection efficiency. Regardless of the sample size the light yield was considerably lower than measured for Li-glass detector. However, $\mathrm{n} / \mathrm{g}$ separation capabilities were deemed as high, and the intrinsic neutron detection efficiency (for the large size sample $-50.8 \mathrm{~mm} \times 2 \mathrm{~mm}$ ) was estimated to $80 \%$ of the Li-glass counterpart.

PSD methods have also been applied to successfully separate neutrons from gamma-ray photons in crystals such as $\mathrm{LiAlO}_{2}$ and $\mathrm{LiGaO}_{2}$ [20]. In this case, Cherenkov radiation can be used to distinguish between neutrons and gammas, as it provides a cut-off point between the fast and slow component in the pulse decay. As tested with ${ }^{252} \mathrm{Cf}$, the researchers show that scintillators are capable of detecting fast neutrons. It is believed that detector's sensitivity could potentially be extended to thermal energy region.

A very good potential for neutron detection via PSD methods is presented by detectors utilising $\mathrm{LiBaF}_{3}$ crystal doped with $\mathrm{Ce}$. The discrimination between various particles, across broad energy spectrum, is possible due to the occurrence of core-valence luminescence (CVL). It is a very short pulse (sub-nanoseconds) resulting from a hole in the conduction band of an ionic crystal that is being filled by an electron travelling from the valence band [10]. It appears alongside the self-trapped exciton (STE) luminescence, when the crystal is exposed to gamma-ray field. When it is exposed to the neutron field, only the STE luminescence is observed. It is reported to have a very decent energy resolution, as well as the ability to discriminate between gamma-, thermal and fast neutrons [21].

Another group of crystals capable of neutron detection are elpasolites, which include scintillators such as $\mathrm{Cs}_{2} \mathrm{LiYCl}_{6}(\mathrm{CLYC})$ and $\mathrm{Cs}_{2} \mathrm{LiLa}(\mathrm{Br}, \mathrm{Cl})_{6}$ (CLLBC). When doped with $\mathrm{Ce}$, these crystals present excellent $\mathrm{n} / \mathrm{g}$ separation characteristics, as well as very high energy resolution [22]. An example of a capability for the use of PSD as a CLYC scintillator is presented in Figure 1. Fast neutron detection can also be facilitated by growing the crystals using ${ }^{7} \mathrm{Li}$, rather than the traditionally used ${ }^{6} \mathrm{Li}$ to maximise thermal neutron sensitivity. Moreover, a number of composite detectors has been developed, composed of a CLYC crystal incorporated into an organic plastic, to further extend the sensitive spectrum to fast neutrons $[23,24]$. 


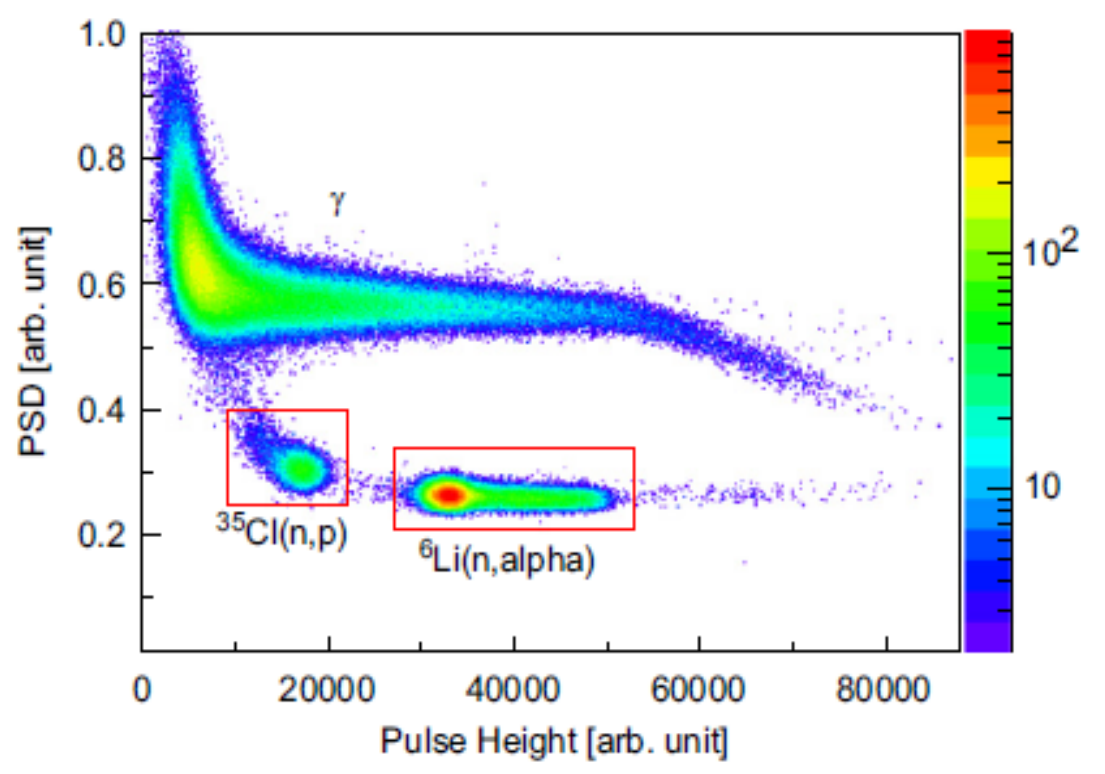

Figure 1. An example of PSD capabilities of $\mathrm{Cs}_{2} \mathrm{LiYCl}_{6}$ (CLYC) scintillator when exposed to a specific neutron field of $1.3 \mathrm{MeV}$ produced by a generator. Taken from the work by the authors of [25].

A further example of an inorganic scintillator for neutron detection that is popularly used is ${ }^{6} \mathrm{LiF} / \mathrm{ZnS}: \mathrm{Ag}$ [26]. At the heart of this scintillator lies ZnS crystalline powder, which was famously used by Rutherford in his work on the stability of atoms [27]. ZnS:Ag powder is characterised by a very good light yield of 75,000 photons $/ \mathrm{MeV}$ and relatively slow decay time of $1.4 \mu$ s [28]. In the same study, the author attempts to characterise pure $\mathrm{ZnS}$ single crystal. The analysis presented suggests that due to the absence of the Ag dopant, the light yield is reduced significantly. It is, therefore, clear that a scintillator in this form would not be capable of detecting neutrons. However, when ${ }^{6} \mathrm{LiF}$ is added to the mix it becomes an efficient thermal neutron detector with low gamma-ray sensitivity. It is commercially available from Eljen Technology as EJ-426 [29].

\subsection{Detectors Utilising Other Properties of Inorganic Crystals}

The ongoing research into finding an appropriate alternative for ${ }^{3} \mathrm{He}$ detector has resulted in new ways of using well established inorganic crystals. One such example is $\mathrm{YAlO}_{3}: \mathrm{Ce}^{3+}$, which was successfully used for gamma radiation detection. Neutron sensitivity was, in this case, facilitated by adding a "converter" in the form of a powder to the surface of the scintillator. Depending on the energy group of neutrons targeted, the possible candidates are lithium, boron, gadolinium (thermal neutrons) and thorium and hydrogen (fast neutrons).

The discrimination between gamma-ray and neutron interaction is performed via pulse height discrimination (PHD) and has been successfully presented with PuBe source [30]. A detector utilising $\mathrm{YAlO}_{3}: \mathrm{Ce}^{3+}$ with neutron converter would benefit from the intrinsic properties of the perovskite detector such as fast decay time, high light yield and good stopping power. Simultaneously, the size of the detector could be kept small which is often desired in applications such as nuclear medicine. However, as with all inorganic scintillation crystals, it is characterised by very high gamma-ray sensitivity, which makes the analysis and discrimination process difficult.

One of the materials mentioned in the preceding paragraph (gadolinium) is characterised by the highest thermal neutron cross-section known. Apart from being used as a converter, gadolinium-based detectors form another group of good fast neutron detecting crystals. $\mathrm{Gd}_{3} \mathrm{Al}_{2} \mathrm{Ga}_{3} \mathrm{O}_{12}$ : $\mathrm{Ce}$ (GAGG:Ce) crystal is characterised by excellent light yield and good stopping power. Neutron interactions with gadolinium are primarily driven by ${ }^{155} \mathrm{Gd}(\mathrm{n}, \gamma)$ and ${ }^{157} \mathrm{Gd}(\mathrm{n}, \gamma)$ reactions, for which the cross-sections 
are 60,900 and 255,000 barns, respectively. The reactions are defined in Equations (3) and (4), where the unstable products return to the ground state with a release of gamma-rays.

The resulting neutron- and gamma-ray-induced pulses must be separated via appropriate method. However, there is no need for material enrichment due to exceptional neutron sensitivity of gadolinium. Moreover, it is possible to retrieve incident kinetic energy of a neutron interacting within the crystal which opens up the possibility of performing neutron spectroscopy. Recent study performed with AmBe source showed a superior performance of this crystal, when compared with an established ${ }^{6} \mathrm{Li}$-glass detector [31]. Given the fast response of the crystal to gamma-ray photons, it is also feasible to explore time-of-flight-based discrimination. Therefore, it comes at no surprise that a lot of research effort is currently going into the improvement of this detector. However, as with most inorganic crystals, high-cost and long growing time may be unacceptable in many applications.

$$
\begin{aligned}
& { }_{64}^{155} \mathrm{Gd}+{ }_{0}^{1} \mathrm{n} \longrightarrow{ }_{64}^{156} \mathrm{Gd}^{*} \longrightarrow{ }_{64}^{156} \mathrm{Gd}+8.54 \mathrm{MeV} \\
& { }_{64}^{157} \mathrm{Gd}+{ }_{0}^{1} \mathrm{n} \longrightarrow{ }_{64}^{158} \mathrm{Gd}^{*} \longrightarrow{ }_{64}^{158} \mathrm{Gd}+7.94 \mathrm{MeV}
\end{aligned}
$$

The detection of thermal neutrons using ${ }^{10} \mathrm{~B}$ reactions is well established in the domain of organic scintillators [32]. Doping with ${ }^{10} \mathrm{~B}$ enables the sensitivity spectrum of organic scintillators, which is a very good fast neutron detector, to be extended to the thermal region. ${ }^{10} \mathrm{~B}(\mathrm{n}, \alpha)$ reactions, as defined in Equations (5) and (6), are probably most widely used mechanism for detection of thermal neutrons, owing to high thermal neutron cross-section (3840 barns) [9]. The reaction can lead to a stable or unstable ${ }^{7} \mathrm{Li}$ isotope and is accompanied by the release of $\alpha$ particle that can be easily detected using conventional methods.

$$
\begin{gathered}
{ }_{5}^{10} \mathrm{~B}+{ }_{0}^{1} \mathrm{n} \longrightarrow{ }_{3}^{7} \mathrm{Li}^{*}+{ }_{2}^{4} \alpha+2.79 \mathrm{MeV} \\
{ }_{5}^{10} \mathrm{~B}+{ }_{0}^{1} \mathrm{n} \longrightarrow{ }_{3}^{7} \mathrm{Li}+{ }_{2}^{4} \alpha+2.31 \mathrm{MeV}
\end{gathered}
$$

Although popular in the domain of organic scintillators, there are not many examples of inorganic crystals utilising ${ }^{10} \mathrm{~B}$-based reactions. However, $\mathrm{Li}_{6} \mathrm{Y}\left(\mathrm{BO}_{3}\right)_{3}$ :Ce has been computationally and experimentally tested, showing good potential for thermal neutron detection. It is reported to be a relatively fast scintillator with a decay time for thermal neutrons of $38 \pm 18 \mathrm{~ns}$, and shows greater thermal neutron detection efficiency than the Li-glass scintillator. However, its light yield is estimated to be six times lower than NaI:Tl, and its $\alpha / \gamma$ ratio is ten times lower than that of Li-glass. The $\alpha / \gamma$ ratio is a measure used to assess scintillator's ability to separate $\alpha$ and $\gamma$ interactions. The assessment is based on the pulse height information. Generally, the light yield produced as a result of $\alpha$ interactions is lower than that resulting from $\gamma$ interactions for the same amount of energy deposited [33]. Another potential area of application for boron doped crystals capable of neutron detection is considered to be space instrumentation, with initial experiments showing reasonable results in regard to thermal neutron detection efficiency [34].

Total neutron cross-section for the discussed elements is presented in Figure 2. It can be observed that gadolinium (shown in yellow) has the highest overall cross-section for the low energy regions. In agreement with the quoted barn values, lithium (shown in orange) has the lowest cross-section out of the three considered candidates. However, there is a noticeable spike between $100 \mathrm{keV}$ and $1 \mathrm{MeV}$ that could be exploited in a specific application targeting this energy region. Boron (shown in grey) appears to be the most stable, out of the three thermal detector options, across the energy spectrum. For comparison, hydrogen's cross-section (shown in blue) is considerably lower than the other three elements in the thermal energy region. Therefore, organic scintillators are primarily used to detect fast neutrons, due to their high hydrogen content. 


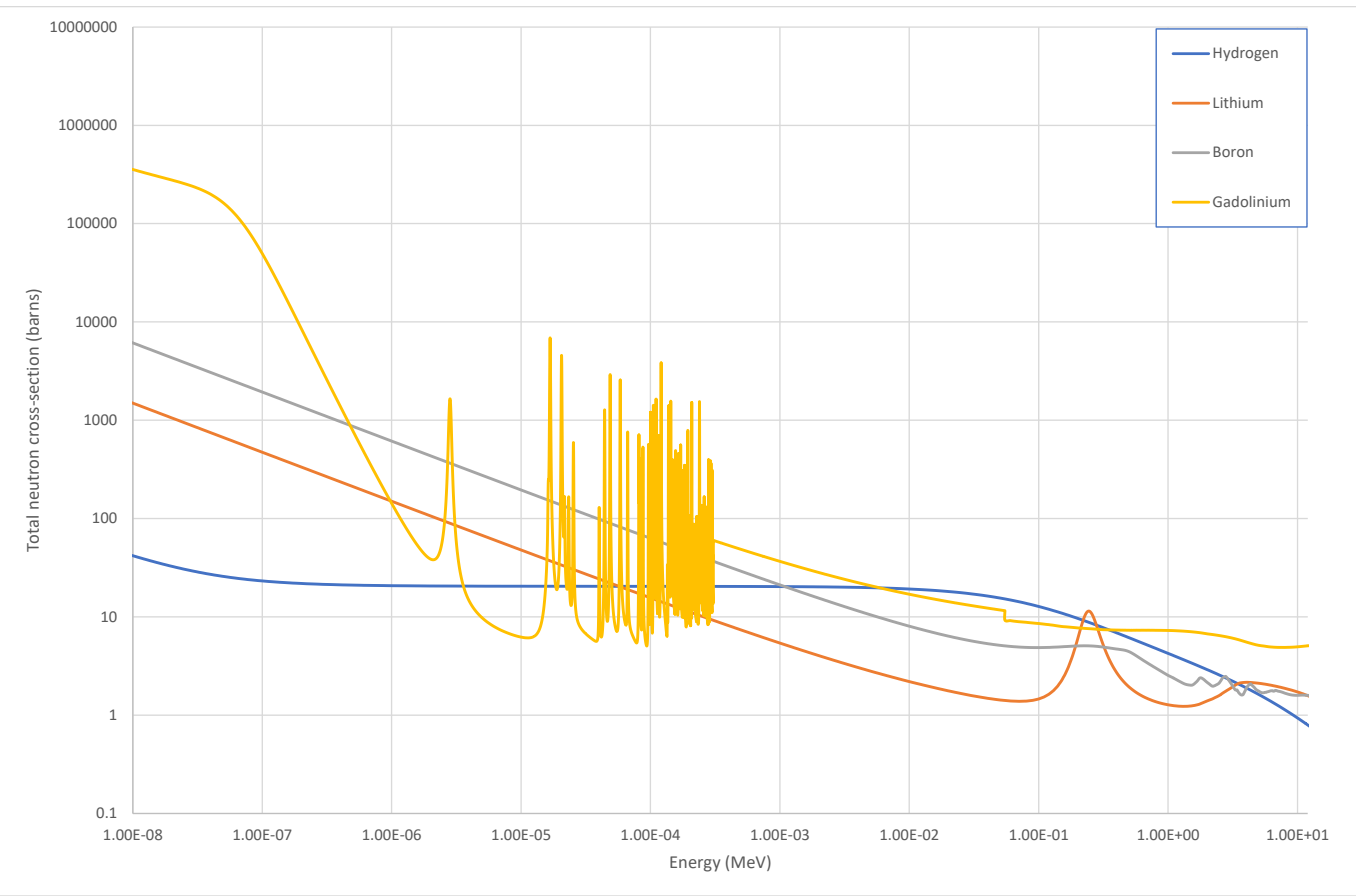

Figure 2. Total neutron cross-sections for the discussed elements: hydrogen, lithium, boron and gadolinium. The cross-sections of the selected isotopes were generated using ENDF/B-VIII.0 libraries.

It is also worth noting that as early as 1968 , it was attempted to perform neutron detection using $\mathrm{NaI}(\mathrm{Tl})$ crystal [35]. The experiment was performed with ${ }^{127}$ I to observe crystal's response to low energy neutrons (via radiative capture) and fast neutrons (inelastic scattering). When tested in a monoenergetic field of $1 \mathrm{MeV}$ neutrons, overall efficiency was measured as $0.5 \%$, considerably lower than that obtained for organic scintillators. As a result, research into suitable fast neutron detection was pursued within the organic scintillators' domain.

Heavy oxide scintillator crystals represent another group of detectors showing potential of neutron detection. The most commonly used examples of this group are the $\mathrm{CdWO}_{4}$ and $\mathrm{PbWO}_{4}$ crystals. $\mathrm{CdWO}_{4}$ is capable of providing a very good spectral response to fast neutrons, but there exist handling issues in some places (e.g., UK) related to this crystal due to toxicity of Cd [36]. Similarly, it has been tested for its fast neutron sensitivity [37]. Despite a relatively good response in comparison to other counterparts tested, its low light yield makes it unsuitable for many applications [22].

\subsection{Organic Crystals Operation}

Regardless of their state (solid or liquid), organic scintillators are generally sensitive to both fast neutrons and gamma-ray photons. Therefore, many PSD methods have been investigated to facilitate low misclassification probability. The difference between the two particles can be inferred from the varying rate of energy loss of the particle, when scattered in the scintillation medium. Fast neutrons primarily undergo elastic scattering with a proton, while gamma-ray photons interact with the atoms of the scintillant via Compton scattering. These result in fluorescence, whose decay time is proportional to the rate of energy loss of the incident particle. Appropriate photodetector is then capable of detecting the fluorescence, and gives rise to a proportional electronic pulse. The rate of energy loss is greater for Compton electrons (resulting from gamma-ray interactions), when compared to protons (resulting from neutron interactions). This difference is reflected in the tail of the electronic pulse produced by the detector [9].

There are only two pure organic crystals that have been widely exploited in radiation detection applications: anthracene and stilbene. Anthracene was popularly used due to its scintillation efficiency, 
which is the greatest of all organic scintillators [9]. The scintillation efficiency of organic scintillators is often quoted as a percentage of anthracence's light output. Stilbene, on the other hand, was characterised by an excellent $\mathrm{n} / \mathrm{g}$ separation capabilities, and was originally used by Brooks [38] when investigating PSD methods in the analogue domain. However, due to the issues related to growing of these crystals in greater dimensions, they have been left aside for many years. In the first decade of the 21st century, an interest has grown back due to new growing methods developed by the team at Lawrence Livermore National Laboratory (LLNL), in the US led by Natalia Zaitseva [39].

Given its excellent light yield, anthracene still remains as the material that is characterised by the best scintillation efficiency available and is often used as a reference when developing new crystals. It was also tested for its PSD capabilities, and, even though inferior to stilbene, decent separation was observed [39]. One of the disadvantages of using organic crystals is their anisotropic response to incident radiation, which affects the performance when the orientation of the detector changes. However, this property can also be exploited to infer the location of the interaction via the angle of the scattered proton. It was successfully used by Brubaker and Steele [40] to perform neutron imaging.

Traditionally, trans-stilbene crystals were grown using the melt growth method. The growth process was associated with both high complexity of the growth process and high cost. Thus, they were only grown in sizes not exceeding $10 \mathrm{~cm}$. However, when a different solution growth method was applied, the growth time was reduced, and samples of greater sizes were grown. It also partially addresses the well-recognised issue of high misclassification between neutrons and gamma-ray photons in the low energy region. Furthermore, when tested in regard to its light yield and PSD capabilities, solution-grown stilbene crystal performed considerably better than equivalent melt-grown stilbene and organic liquid scintillator-EJ-309 [41]. It also shows better PSD characteristics than other PSD plastic scintillators [42].

As a solid, non-hygroscopic, not hazardous material, lightweight stilbene crystal is suitable for many applications such as nuclear decommissioning and portable security devices [43]. Although it is now possible to grow these crystals in larger sizes, the cost of manufacturing is still relatively high, suggesting that organic liquids may still be more cost effective for large scale detectors. Nevertheless, the continuous interest in the field of organic crystals has led to the development of a new stilbene crystal, where hydrogen is replaced with deuterium. This deuterated stilbene is reported to have even better PSD capabilities than the standard stilbene [44]. Another organic crystal that should be mentioned at this stage is rubrene crystal, which is also grown from solution and is reported to show clear response to $\alpha$ particles, and a moderate response to fast neutrons [45].

Based on the presentation of the scintillating crystals currently utilised in neutron detection applications, there is no single choice to account for all the requirements of a neutron detector. Therefore, it is essential to carefully analyse the requirements of a detector and choose the sensitive material accordingly. In the following section, a practical example of an organic stilbene crystal tested in the mixed field of ${ }^{252} \mathrm{Cf}$, in regard to its pulse shape discrimination capabilities is presented. This particular scintillator was chosen, as it illustrates the feature of lower misclassification probability at lower neutron energies. Results obtained are then analysed, and the article is concluded with the future outlook for scintillating crystals in neutron detection field.

\subsection{Summary}

There exist a vast number of scientific resources available, where the most important properties of scintillating materials have been documented. However, these are generally focusing on specific particles (e.g., gamma-ray detectors) or subset of the particle group (e.g., thermal neutrons). In this work, an attempt was made to present the properties of the most promising candidates that have been examined in respect to neutron detection potential. In Table 1, a comparison of the selected inorganic and organic scintillating crystals is shown. A broad range of materials is covered, including both inorganic and organic crystals, capable of gamma-ray detection as well as $\mathrm{n} / \mathrm{g}$ detection. For comparison, typical liquid and plastic scintillators are also included. 
Table 1. Comparison of the most prominent properties of scintillating crystals capable of gamma-ray and $\mathrm{n} / \mathrm{g}$ detection. Data presented below was compiled based on the works by the authors of $[9,20,46-58]$.

\begin{tabular}{|c|c|c|c|c|c|c|c|}
\hline \multirow[t]{2}{*}{$\begin{array}{l}\text { Scintillation } \\
\text { Material }\end{array}$} & \multirow[t]{2}{*}{$\begin{array}{c}\text { Density } \\
\left(\mathrm{gm} / \mathrm{cm}^{3}\right)\end{array}$} & \multirow[t]{2}{*}{$\begin{array}{l}\text { Wavelength } \\
\quad(\mathrm{nm})\end{array}$} & \multirow[t]{2}{*}{ Refractive Index } & \multirow[t]{2}{*}{$\begin{array}{c}\text { Decay Time } \\
\text { (ns) }\end{array}$} & \multicolumn{2}{|c|}{$\begin{array}{c}\text { Light Yield } \\
\text { (Photons/MeV) }\end{array}$} & \multirow[t]{2}{*}{$\begin{array}{l}\text { Energy Resolution } \\
\text { (\% at } 662 \mathrm{keV})\end{array}$} \\
\hline & & & & & Neutron & Gamma & \\
\hline $\mathrm{NaI}(\mathrm{Tl})$ & 3.67 & 415 & 1.85 & 230 & - & 41,000 & 5.6 \\
\hline CsI(Tl) & 4.51 & 550 & 1.8 & 800 & - & 66,000 & 6.6 \\
\hline CsI(Na) & 4.51 & 420 & 1.84 & 630 & - & 40,000 & 7.4 \\
\hline LSO(Ce) & 7.4 & 420 & 1.82 & 40 & - & 26,000 & 7.9 \\
\hline LYSO(Ce) & 7.2 & 400 & 1.81 & $30-35$ & - & 32,000 & 8.5 \\
\hline LiI(Eu) & 4.1 & 470 & 1.96 & 1400 & 50,000 & 12,000 & 8 \\
\hline $\mathrm{LiCaAlF}_{6}(\mathrm{Eu})$ & 2.94 & 370 & 1.4 & 40 & 30,000 & 29,000 & - \\
\hline $\mathrm{LiCaAlF}_{6}(\mathrm{Ce})$ & 2.94 & 300 & 1.4 & 40 & 4,000 & 1,600 & - \\
\hline $\mathrm{LiAlO}_{2}$ & 2.61 & 330 & - & 790 (5400 not enriched $\left.{ }^{6} \mathrm{Li}\right)$ & 5,900 & 7,000 & - \\
\hline $\mathrm{LiGaO}_{2}$ & 4.18 & 330 & - & $\left.12(680 \text { not enriched })^{6} \mathrm{Li}\right)$ & 5,500 & 5,000 & - \\
\hline CLYC & 3.3 & 380 & 1.81 & $50 ; 1,000$ & 70,000 & 20,000 & 4 \\
\hline CLLBC & 4.1 & 410 & 1.9 & $55 ;<270$ & 180,000 & 60,000 & 3.5 \\
\hline${ }^{6} \mathrm{LiF} / \mathrm{ZnS}: \mathrm{Ag}$ & 2.6 & 450 & - & $\begin{array}{c}80,000 \text { (neutron), } \\
100 \text { (gamma) }\end{array}$ & 160,000 & 75,000 & - \\
\hline $\mathrm{YAl0}_{3}: \mathrm{Ce}^{3+}$ & 5.37 & 370 & 1.95 & 30 & - & 21,000 & 4.3 \\
\hline GAGG:Ce & 6.63 & 520 & 1.9 & 100 & - & 56,000 & - \\
\hline $\mathrm{Li}_{6}\left(\mathrm{BO}_{3}\right)_{3}: \mathrm{Ce}$ & 2.8 & 420 & - & 27 & - & 1,200 & - \\
\hline $\mathrm{CdWO}_{4}$ & 7.9 & 495 & - & 5000 & - & 20,000 & 6.8 \\
\hline $\mathrm{PbWO}_{4}$ & 8.28 & 420 & 2.16 & $6 ; 30$ & - & 205 & - \\
\hline Stilbene & 1.25 & 390 & 1.626 & $3.5-4.5$ & 10,700 & 14,000 & - \\
\hline Anthracene & 1.16 & 447 & 1.62 & 30 & 20,000 & 20,000 & - \\
\hline EJ-309 & 0.96 & 424 & 1.57 & 3.5 (short component) & 12,300 & 12,300 & - \\
\hline EJ-276 & 1.096 & 425 & - & $\mathrm{g}(13,35,270) ; \mathrm{n}(13,59,460)$ & 8,600 & 8,600 & - \\
\hline
\end{tabular}

The data in Table 1 presents a list of potential candidates for the specific applications with regard to the target particle types. There are two particular materials that bring the distinct advantages to $\mathrm{n} / \mathrm{g}$ detection and are aimed at different areas of the neutron energy spectrum. In the region of thermal neutrons, CLYC appears to be a very promising candidate, as it presents a very decent results across the considered properties, and its PSD capabilities are exceptional, as presented in Figure 1.

Fast neutron detection is primarily targeted by organic scintillation materials. These are presented in the last four rows of Table 1. It can be noticed that continuous development of the new crystal growing methods results in improved light yield of stilbene crystal which used to only achieve $~ 50 \%$ of anthracene's yield [9]. Similarly to CLYC for thermal neutrons, stilbene's PSD performance is superior to other organic scintillators in the region of fast neutrons. A comparison of stilbene's PSD performance to that of plastic scintillator is shown in further section of this article.

\section{Methodology}

This section describes the methodology of the work performed in order to present the PSD potential of single stilbene crystal through a comparison of its performance with that of an organic plastic scintillator. Firstly, the energy calibration process is described. It is followed by the description of a PSD technique used in this experiment, and concluded with the explanation of the PSD quality assessment method used in this study.

\subsection{Energy Calibration}

Prior to the experiments performed within the mixed-field environment of ${ }^{252} \mathrm{Cf}$ both scintillators were calibrated using ${ }^{137} \mathrm{Cs}$ gamma-ray source of $319 \mathrm{kBq}$ current activity. Each detector assembly was, 
in turn, exposed to the gamma-ray field of ${ }^{137} \mathrm{Cs}$ by placing the detector assembly $15 \mathrm{~cm}$ away from the point source. Each detected pulse was processed through a bespoke pile-up rejection algorithm where a pulse was rejected if two peaks within one trigger window were detected. Also, baseline subtraction was performed by calculating the average over the periods before and after the pulse within the trigger window. Given that the pulse was detected between sample no. 50 and 100, the baseline was calculated over samples 1-45 and 105-128. There were 104,069 pulses accepted for the plastic scintillator sample and 74,684 pulses for the single stilbene crystal. These were subsequently used to plot the pulse height spectra, as presented in Figure 3, and adjust the equivalent energy scale for PSD considerations.

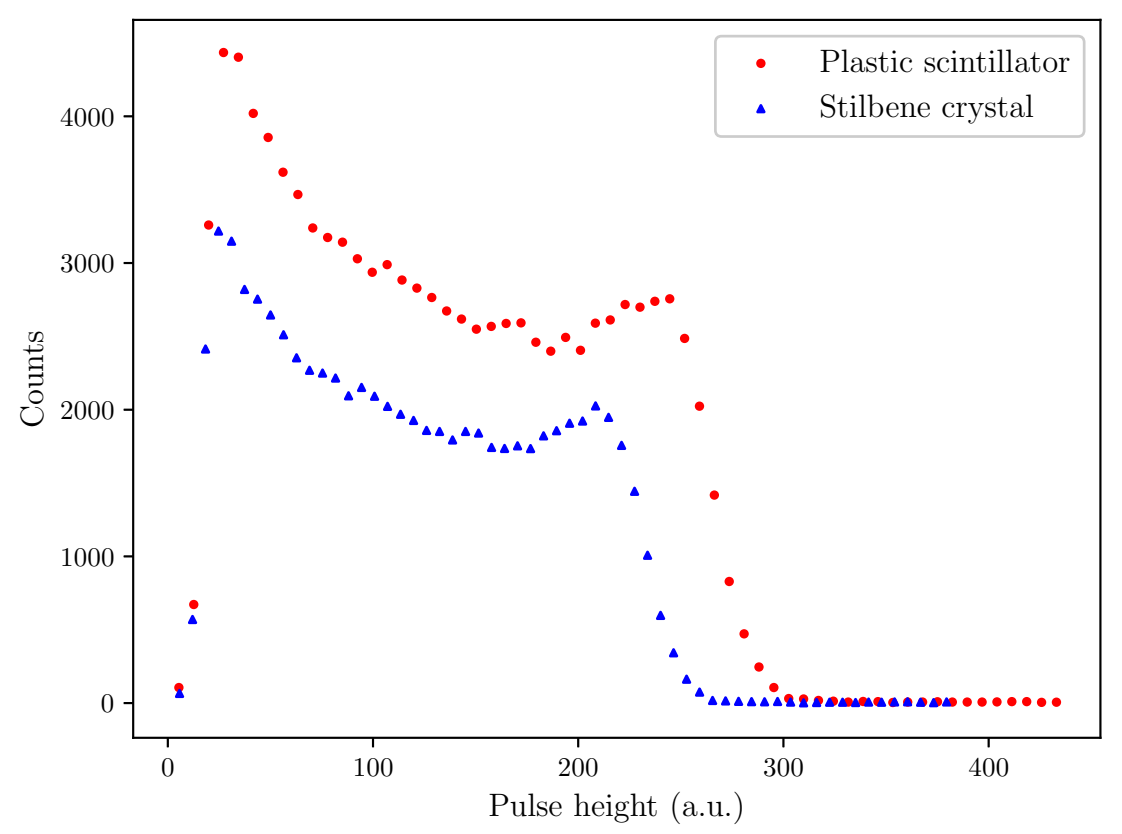

Figure 3. Pulse height spectra of each scintillator obtained with ${ }^{137} \mathrm{Cs}$ used to perform energy calibration of the detectors.

\subsection{Pulse Shape Discrimination}

In order to illustrate the capabilities of organic scintillators in regard to fast neutron detection, two solid state organic detectors have been tested in the mixed-field $(\mathrm{n} / \gamma)$ environment provided by ${ }^{252} \mathrm{Cf}$ at Lancaster University, UK. A single stilbene organic crystal scintillator was obtained from Inrad Optics in 2016. PSD performance of this cylindrical crystal $(20 \mathrm{~cm} \times 20 \mathrm{~cm})$ was compared with that of an organic plastic cylindrical sample $(25.4 \mathrm{~cm} \times 25.4 \mathrm{~cm})$ obtained from Lawrence Livermore National Laboratory (LLNL) in the US, with LLNL sample number 5706. Samples have been covered with reflective coating on the side and back to minimise the chance of photons escaping the scintillator without being detected. Each scintillator was then, in turn, attached to a single channel ET Enterprises 9107B PMT using EJ-550 silicon grease. The PMT anode signals were collected via FPGA based signal digitiser operating at the sampling frequency of $500 \mathrm{MS} / \mathrm{s}$ with 12-bit resolution.

The complete assembly, comprising scintillator and the PMT, was placed in a cylindrical light-proof box and placed in front of the water tank, where the radioactive isotope is normally stored. The radioactive source is normally located in the centre of a water-filled tank, as shown in Figure 4. For experiments the source is pneumatically moved to the edge of the tank, which stops $\sim 20 \mathrm{~cm}$ away from the edge. The detector assembly was placed $15 \mathrm{~cm}$ away from the edge of the tank, resulting in the total distance of $35 \mathrm{~cm}$ between the source and the detector front. Each scintillator was exposed for the duration of 1 hour. The FPGA based digitiser collected raw data, with each sample collected every 2 ns. Detection window consisted of 128 samples, collected over $256 \mathrm{~ns}$ trigger period. 


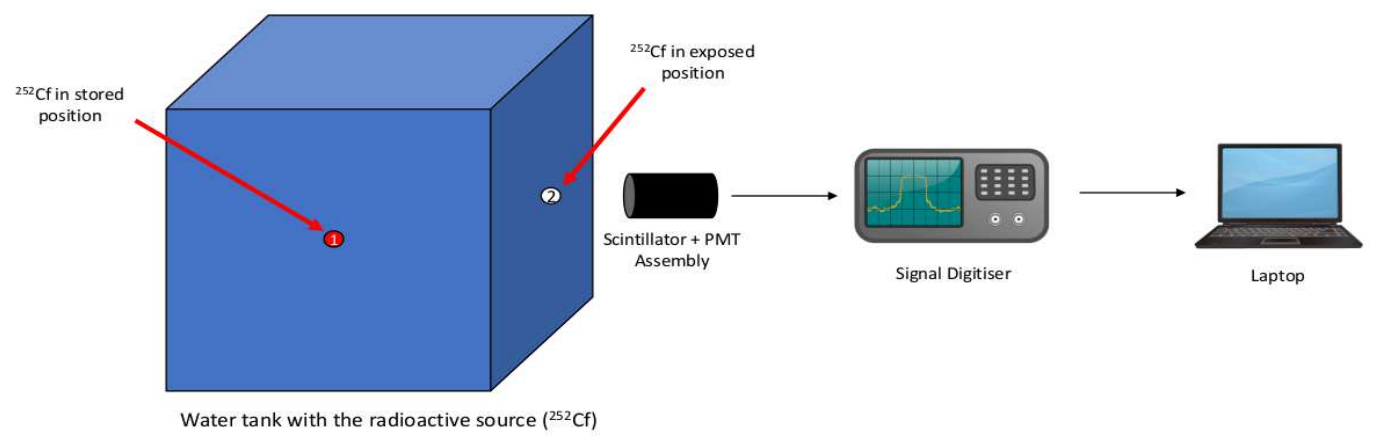

Figure 4. Diagram presenting the experimental set-up, with the radioactive isotope in the centre of a water-filled steel tank (position 1), where it is normally stored. For experiments the source is pneumatically moved to the edge of the tank (position 2).

Before any further analysis was performed, the quality of each pulse detected was assessed through the pile-up rejection algorithm in the same way as for the energy calibration. Similarly, the baseline removal was performed. Charge Comparison Method (CCM) was applied in the digital domain to assess $\mathrm{n} / \mathrm{g}$ separation capabilities of the scintillator samples.

The CCM is the most popular method, where the pulse is analysed by calculating integrals over two different time intervals [38]. As the difference between the neutron and gamma-ray induced interactions is most prominent in the tail of the pulse, the "short integral" is calculated between a point some time after the peak of the pulse and the end of the pulse, as specified in Figure 5. The "long integral" is calculated over the entire duration of the pulse. These can then be used to calculate the discrimination factor, as described below, and generate a plot exploiting the PSD capabilities of the detector.

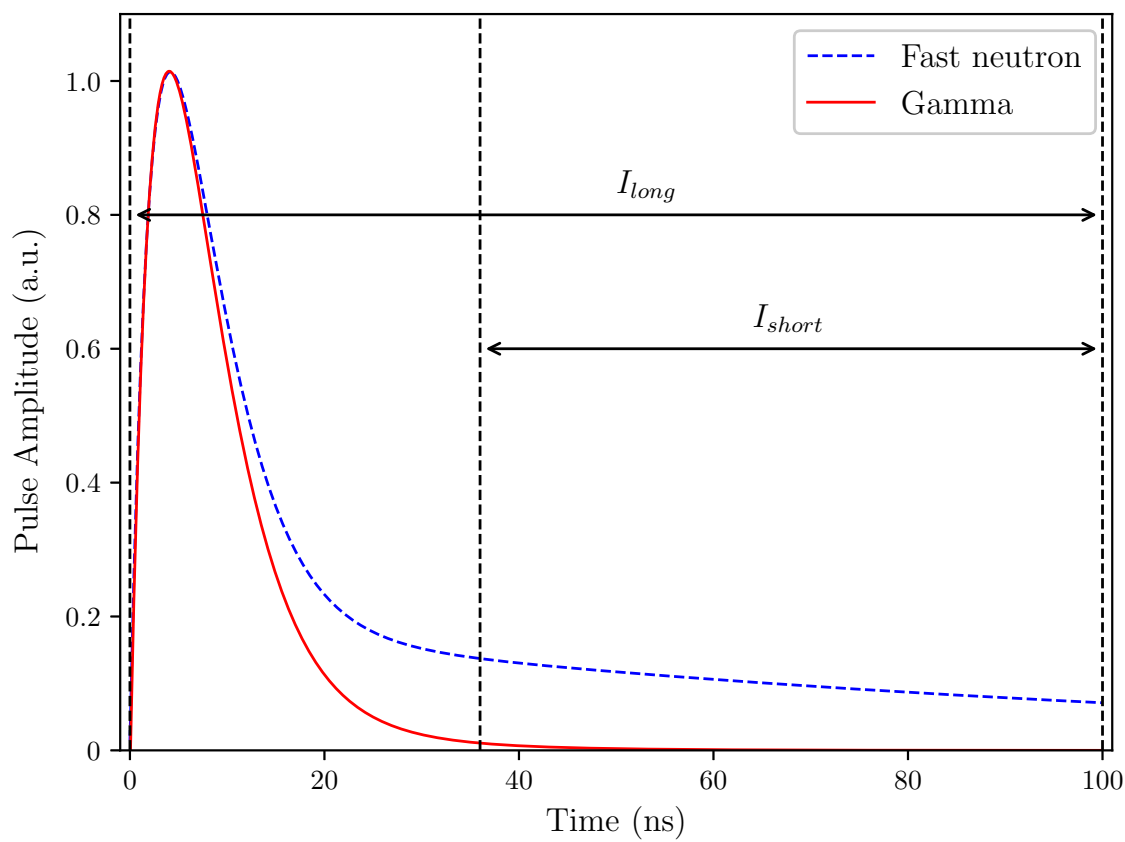

Figure 5. Illustration of the implementation of the pulse shape discrimination method used in this study. Long and short integrals used in CCM calculations are clearly marked on the plot. Theoretical fast neutron and gamma-ray pulses were obtained based on the data from Knoll [9] and Zaitseva et al. [59].

There are numerous ways of presenting the implementation results of CCM. One of the most reliable methods is to calculate a discrimination factor and present it with respect to the electron 
equivalent energy for each detected interaction. In this work, the discrimination factor $\mathrm{D}_{\mathrm{f}}$ was calculated using the equation presented in Equation (7). The remaining terms in Equation (7) ( $\mathrm{I}_{\text {short }}, \mathrm{I}_{\text {long }}$ ) correspond to the integrals introduced in Figure 5. The discrimination factor was then plotted against the equivalent energy of the pulse, following the calibration process described in the preceding subsection.

$$
D_{f}=1-\frac{I_{\text {short }}}{I_{\text {long }}}
$$

\subsection{PSD Quality Assessment}

The concept of FOM as a measure for particle separation quality was originally introduced by Winyard et al. [60]. In order to estimate the FOM, the data needs to be presented in a form of a plot, where the distribution of the particles is illustrated. For neutrons and gamma-ray photons it is expected that they will show normal distribution spread. An example n/g distribution is presented in Figure 6. Terms identified in Figure 6 are then used to calculate the FOM, as presented in Equation (8).

$$
\mathrm{FOM}=\frac{\text { Peak separation }}{F W H M_{g}+F W H M_{n}}
$$

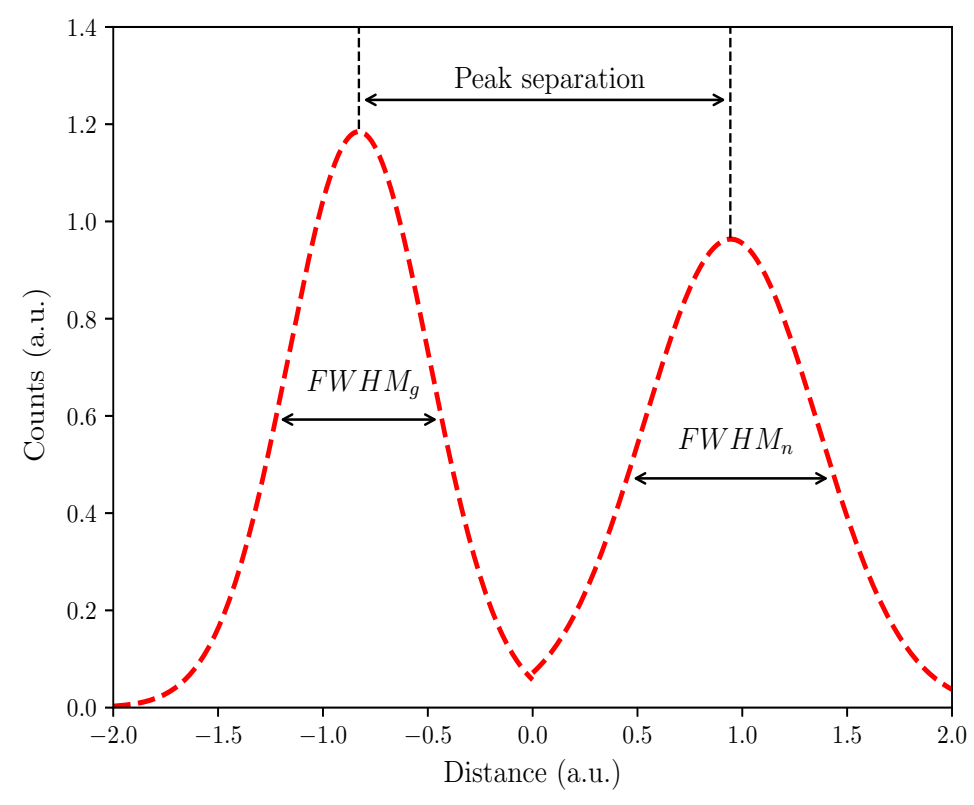

Figure 6. Example neutron and gamma-ray distributions based on the distance to the discrimination line.

\section{Results}

Each scintillator was, in turn, exposed to the mixed-field environment provided by ${ }^{252} \mathrm{Cf}$ for the duration of $60 \mathrm{~min}$. There were 902,564 pulses accepted for the plastic scintillator sample, and 840,583 pulses for the organic crystal sample. The PSD scatter plots for each sample are presented in Figure 7a (plastic) and Figure $7 \mathrm{~b}$ (crystal). Discrimination factor, $\mathrm{D}_{\mathrm{f}}$, as defined in previous sections, has been plotted against the electron equivalent energy. The resulting plumes represent the neutron and gamma-ray photon interactions, with gamma-rays depicted by the upper plume and neutrons by the lower plume. 


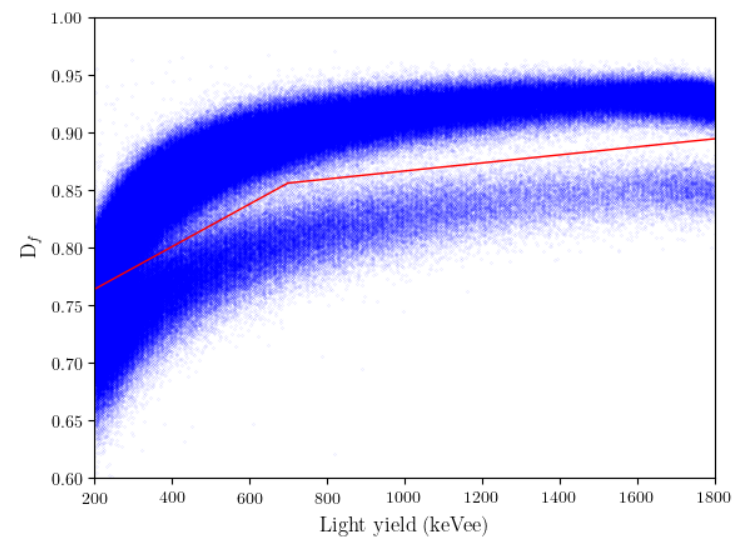

(a)

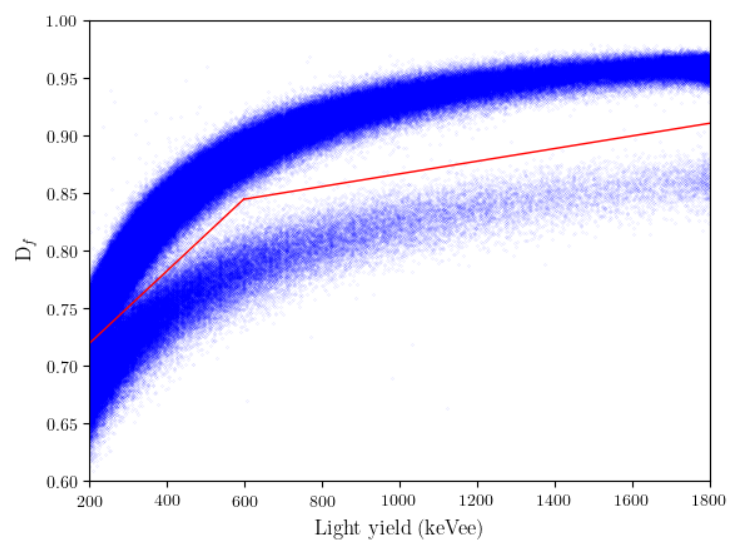

(b)

Figure 7. Comparison of Charge Comparison Method (CCM) plots for the two organic scintillator samples when exposed to ${ }^{252} \mathrm{Cf}$ and data were collected with $500 \mathrm{MS} / \mathrm{s}$ digitiser: (a) Cylindrical pulse shape discrimination (PSD) plastic from LLNL and (b) single stilbene crystal. The upper plume is associated with gamma-ray interactions, whereas the lower plume with neutron events.

Next, PSD separation quality was assessed for each scintillator using FOM. Given the way data are presented in this study, a discrimination line was plotted to mark the visible separation between the plumes. The distance from each point to the discrimination line was then plotted in form of a histogram in order to show the distribution of the considered particles. This method was used to estimate the FOM in the current study, with the resulting values of 0.637 for the plastic and 0.892 for the crystal scintillator sample.

\section{Discussion and Conclusions}

Given the increasing need for reliable neutron detection alternatives for ${ }^{3} \mathrm{He}$ detectors, the authors attempted to present a review of the most viable options available among the crystal scintillators. Given the complexity of neutron detection, various methods are required to target specific neutron energy range. Both organic and inorganic options were considered. Each group presents advantages for certain application areas.

It appears that inorganic crystals utilising isotopes with high thermal neutron cross-section (lithium, boron and gadolinium) provide a very good alternative for low energy neutron detectors. However, the manufacturing cost is still high, and the growing process is long. Fast neutron region, on the other hand, has been targeted by organic scintillators for a long time, due to ${ }^{1} \mathrm{H}$ content, which allows elastic scattering of neutrons with a proton. Stilbene crystal is arguably the best available scintillator detector capable of $\mathrm{n} / \mathrm{g}$ separation. Nonetheless, growing large size detectors using stilbene crystals is expensive in comparison to organic plastics and liquids.

There have been attempts to develop a neutron detector targeting a larger energy spectrum. However, due to different mechanisms governing neutron interactions with matter at various energy levels, this is not possible with a single material detector. Up to date literature reports on multidetector systems, where different detectors are used independently to detect specific group of neutrons. Readout electronics attached to such system can combine the results into one system. Another method, stemming from the multidetector approach described, is based on composite detectors, where a detector such as CLYC is incorporated into plastic scintillator to detect gammas, and thermal and fast neutrons. Regardless of the target energy range, it is clear that scintillating crystals will continue to play a key role in neutron detectors. 


\section{Example of Neutron Detection Capabilities Using Single Stilbene Crystal}

An example of detecting neutrons originating from ${ }^{252} \mathrm{Cf}$ using organic solid state scintillators is presented in Figure 7. Due to scintillators' sensitivity to neutrons and gamma-ray photons, both particle types are detected resulting in two corresponding plumes. These tend to overlap slightly in the low energy level. A significant overlap in that region leads to higher probability of particle misclassification. As evidenced by the plots in Figure 7, the overlap is most prominent in the low energy region. To illustrate the difference in PSD performance in the low energy region between the two scintillator sample, the low energy limit was set to $200 \mathrm{keVee}$. The high energy limit was set to 1800 keVee for both scintillators.

Based solely on the observation of the two graphs presented in Figure 7, it is clear that the single stilbene crystal (Figure 7b) provides superior PSD, when compared with the LLNL plastic sample (Figure 7a). Given that a similar number of pules was accepted by the system for each scintillator, the shape and intensity of the plumes appear quite dissimilar. Most importantly, the low energy cut-off point can be observed at $\sim 300$ keVee for the single stilbene crystal. The corresponding cut-off point for the plastic scintillator is found at $\sim 400 \mathrm{keVee}$. Moreover, the overlap in the low energy area is visibly smaller for the single stilbene than it is for plastic. The density of each plume is also higher for the stilbene crystal which again allows PSD to be performed with the higher level of accuracy.

These general observations agree with the quantitative analysis performed. The FOM was estimated for each detector, where 0.637 was observed for the plastic and 0.892 for the single stilbene crystal. Despite the various unique considerations required in the process of FOM estimation, presented results strongly support the claim that stilbene crystal is characterised by significantly superior PSD for fast neutron detection. The FOM estimated for stilbene crystal is considerably higher than the FOM value calculated for the plastic.

Author Contributions: This work was completed with contribution from all three authors. M.J.C. performed the experimental work and prepared the original manuscript. K.A.A.G. and R.G. performed a detailed review of the manuscript.

Funding: The authors would like to acknowledge the funding support from EPSRC (grant number EP/M507891/1) via Faculty of Science and Technology, Lancaster University, U.K. and Sellafield Ltd., UK.

Acknowledgments: The authors would like to express their gratitude to Natalia Zaitseva and the team at LLNL for providing the plastic scintillator sample. The authors also acknowledge the use of the Matplotlib package for all plots presented in this paper [61].

Conflicts of Interest: The authors declare no conflicts of interest.

\section{References}

1. Osovizky, A.; Ginzburg, D.; Manor, A.; Seif, R.; Ghelman, M.; Cohen-Zada, I.; Ellenbogen, M.; Bronfenmakher, V.; Pushkarsky, V.; Gonen, E.; et al. SENTIRAD-An innovative personal radiation detector based on a scintillation detector and a silicon photomultiplier. Nucl. Inst. Methods Phys. Res. A 2011, 652, 41-44. [CrossRef]

2. Seymour, R.; Hull, C.D.; Crawford, T.; Coyne, B.; Bliss, M.; Craig, R.A. Portal, freight and vehicle monitor performance using scintillating glass fiber detectors for the detection of plutonium in the Illicit Trafficking Radiation Assessment Program. J. Radioanal. Nucl. Chem. 2001, 248, 699-705. [CrossRef]

3. Röntgen, W.C. On a New Kind of Rays. Science 1896, 3, 227-231. [CrossRef] [PubMed]

4. Crookes, W. On The Illumination of Lines of Molecular Pressure and the Trajectory of Molecules. Philos. Trans. R. Soc. Lond. 1878, 28, 102-111.

5. Friedrich, W.; Knipping, P.; Laue, M. Interferenzerscheinungen bei Röntgenstrahlen. Ann. Phys. 1913, 346, 971-988. [CrossRef]

6. Bragg, W.H. X-Rays and Crystalline Structure. Science 1914, 40, 795-802. [CrossRef] [PubMed]

7. Zworykin, V.K.; Morton, G.A.; Malter, L. The Secondary Emission Multiplier-A New Electronic Device. Proc. Inst. Radio Eng. 1936, 24, 351-375. [CrossRef]

8. Krane, K.S. Introductory Nuclear Physics; Wiley: New York, NY, USA, 1988. 
9. Knoll, G.F. Radiation Detection and Measurement, 4th ed.; John Wiley \& Sons: Hoboken, NJ, USA, 2010.

10. Van Eijk, C.W. Development of inorganic scintillators. Nucl. Inst. Methods Phys. Res. Sec. A Accel. Spectrom. Detec. Assoc. Equip. 1997, 392, 285-290. [CrossRef]

11. Schweitzer, J.S. Cerium-doped Lutetium Oxyorthosilicate. IEEE Trans Nucl Sci. 1992, 39, 502-505.

12. Tomanin, A.; Peerani, P.; Janssens-Maenhout, G. On the optimisation of the use of ${ }^{3} \mathrm{He}$ in radiation portal monitors. Nucl. Inst. Methods Phys. Res. A 2012, 700, 81-85. [CrossRef]

13. Kouzes, R.T.; Ely, J.H.; Erikson, L.E.; Kernan, W.J.; Lintereur, A.T.; Siciliano, E.R.; Stephens, D.L.; Stromswold, D.C.; Van Ginhoven, R.M.; Woodring, M.L. Neutron detection alternatives to ${ }^{3}$ He for national security applications. Nucl. Inst. Methods Phys. Res. Sec. A Accel. Spectrom. Detec. Assoc. Equip. 2010, 623, 1035-1045. [CrossRef]

14. Robinson, S.M.; Runkle, R.C.; Newby, R.J. A comparison of performance between organic scintillation crystals and moderated ${ }^{3} \mathrm{He}-$ based detectors for fission neutron detection. Nucl. Inst. Methods Phys. Res. A 2011, 652, 404-407. [CrossRef]

15. Peerani, P.; Tomanin, A.; Pozzi, S.; Dolan, J.; Miller, E.; Flaska, M.; Battaglieri, M.; Vita, R.D.; Ficini, L.; Ottonello, G.; et al. A Testing on novel neutron detectors as alternative to ${ }^{3} \mathrm{He}$ for security applications $\mathrm{Nucl}$. Instrum. Methods Phys. Res. Sect. A Accel. Spectrom. Detect. Assoc. Equip. 2012, 696, 110-120. [CrossRef]

16. Goldsmith, J.E.M.; Gerling, M.D.; Brennan, J.S. A compact neutron scatter camera for field deployment A compact neutron scatter camera for field deployment. Rev. Sci. Instrum. 2019, 87, 083307. [CrossRef] [PubMed]

17. Balmer, M.J.; Gamage, K.A.; Taylor, G.C. Comparative analysis of pulse shape discrimination methods in a 6Li loaded plastic scintillator. Nucl. Inst. Methods Phys. Res. Sec. A Accel. Spectrom. Detec. Assoc. Equip. 2015, 788, 146-153. [CrossRef]

18. Boatner, L.; Comer, E.; Wright, G.; Ramey, J.; Riedel, R.; Jellison, G.; Kolopus, J. Improved Lithium Iodide neutron scintillator with $\mathrm{Eu}^{2+}$ activation II: Activator zoning and concentration effects in Bridgman-grown crystals. Nucl. Inst. Methods Phys. Res. Sec. A Accel. Spectrom. Detec. Assoc. Equip. 2018, 903, 8-17. [CrossRef]

19. Iwanowska, J.; Swiderski, L.; Moszynski, M.; Yanagida, T.; Yokota, Y.; Yoshikawa, A.; Fukuda, K.; Kawaguchi, N.; Ishizu, S. Thermal neutron detection with $\mathrm{Ce}^{3+}$ doped LiCaAlF 6 single crystals. Nucl. Inst. Methods Phys. Res. Sec. A Accel. Spectrom. Detec. Assoc. Equip. 2011, 652, 319-322. [CrossRef]

20. Yanagida, T.; Watanabe, K.; Okada, G.; Kawaguchi, N. Neutron and gamma-ray pulse shape discrimination of $\mathrm{LiAlO}_{2}$ and $\mathrm{LiGaO}_{2}$ crystals. Nucl. Inst. Methods Phys. Res. Sec. A Accel. Spectrom. Detec. Assoc. Equip. 2019, 919, 64-67. [CrossRef]

21. Reeder, P.L.; Bowyer, S.M. Fast neutron and alpha detection using LiBaF3 scintillator. IEEE Trans. Nucl. Sci. 2001, 48, 351-355. [CrossRef]

22. Glodo, J.; Wang, Y.; Shawgo, R.; Brecher, C.; Hawrami, R.H.; Tower, J.; Shah, K.S. New Developments in Scintillators for Security Applications. Phys. Proc. 2017, 90, 285-290. [CrossRef]

23. Gueorguiev, A.; van Loef, E.; Markosyan, G.; Soundara-Pandian, L.; Glodo, J.; Tower, J.; Shah, K. Composite neutron gamma detector. In Proceedings of the 2015 IEEE Nuclear Science Symposium and Medical Imaging Conference (NSS/MIC), San Diego, CA, USA, 31 October-7 November 2015; pp. 1-3. [CrossRef]

24. Shirwadkar, U.; Gueorguiev, A.; van Loef, E.V.; Markosyan, G.; Glodo, J.; Tower, J.; Shah, K.S.; Pozzi, S.; Clarke, S.; Bourne, M. Multi-Signature Composite Detector System for Nuclear Non-proliferation. In Proceedings of the 2017 IEEE Nuclear Science Symposium and Medical Imaging Conference (NSS/MIC), Atlanta, GA, USA, 21-28 October 2017; pp. 1-4. [CrossRef]

25. D’Olympia, N.; Chowdhury, P.; Lister, C.J.; Glodo, J.; Hawrami, R.; Shah, K.; Shirwadkar, U. Pulse-shape analysis of CLYC for thermal neutrons, fast neutrons, and gamma-rays. Nucl. Inst. Methods Phys. Res. Sec. A Accel. Spectrom. Detec. Assoc. Equip. 2013, 714, 121-127. [CrossRef]

26. Van Eijk, C.W. Inorganic scintillators for thermal neutron detection. Radiat. Measur. 2004, 38, 337-342. [CrossRef]

27. Rutherford, S.E. The Stability of Atoms. Proc. Phys. Soc. Lond. 1920, 33, 389-394. [CrossRef]

28. Yanagida, T.; Fujimoto, Y. Evaluations of pure zinc sulfide crystal scintillator. Jpn. J. Appl. Phys. 2014, 53, 032601. [CrossRef]

29. Eljen Technology. EJ-426 Thermal Neutron Detector Data Sheet. 2016. Available online: https:/ / eljentechnology. com/images/products/data_sheets/EJ-426.pdf (accessed on 11 September 2019). 
30. Viererbl, L.; Klupak, V.; Vins, M.; Lahodova, Z.; Soltes, J. YAP:Ce Scintillator Characteristics for Neutron Detection. IEEE Trans. Nucl. Sci. 2016, 63, 1963-1966. [CrossRef]

31. Korjik, M.; Brinkmann, K.T.; Dosovitskiy, G.; Dormenev, V.; Fedorov, A.; Kozlov, D.; Mechinsky, V.; Zaunick, H.G. Compact and Effective Detector of the Fast Neutrons on a Base of Ce-doped $\mathrm{Gd}_{3} \mathrm{Al}_{2} \mathrm{Ga}_{3} \mathrm{O}_{12}$ Scintillation Crystal. IEEE Trans. Nucl. Sci. 2019, 66, 536-540. [CrossRef]

32. Iwanowska, J.; Szczeęśniak, T.; Szczęśniak, T. New Organic Scintillators for Neutron Detection. Aip Conf. Proc. 2010, 1204, 165. [CrossRef]

33. Fu, Z.; Pan, S.; Yang, F.; Gu, S.; Lei, X.; Heng, Y.; Ren, G.; Qi, M. Neutron detection properties of $\operatorname{Li}_{6} \mathrm{Y}\left(\mathrm{BO}_{3}\right)_{3}: \mathrm{Ce}$ crystal. Radiat. Meas. 2015, 72, 39-43. [CrossRef]

34. Hansson, C.C.T.; Owens, A.; Biezen, J.V.D. X-ray, $\gamma$-ray and neutron detector development for future space instrumentation. Acta Astronaut. 2013, 93, 121-128. [CrossRef]

35. Inada, T. Detection of Fast Neutrons with Nal(Tl) Crystal. J. Nucl. Sci. Technol. 1968, 5, 287-291. [CrossRef]

36. Ryzhikov, V.D.; Naydenov, S.V.; Onyshchenko, G.M.; Piven', L.A.; Pochet, T.; Smith, C.F. High efficiency fast neutron detectors based on inorganic scintillators. In Proceedings of the 2014 IEEE Nuclear Science Symposium and Medical Imaging Conference (NSS/MIC), Seattle, WA, USA, 8-15 November 2014; pp. 1-6. [CrossRef]

37. Lucchini, M.; Pauwels, K.; Pizzichemi, M.; Chipaux, R.; Jacquot, F.; Mazué, H.; Wolff, H.; Lecoq, P.; Auffray, E. Response of Inorganic Scintillators to Neutrons of 3 and $15 \mathrm{MeV}$ Energy. IEEE Trans. Nucl. Sci. 2014, 61, 472-478. [CrossRef]

38. Brooks, F. A scintillation counter with neutron and gamma-ray discriminators. Nucl. Instrum. Methods 1959, 4, 151-163. [CrossRef]

39. Hull, G.; Zaitseva, N.P.; Cherepy, N.J.; Newby, J.R.; Stoeffl, W.; Payne, S.A. New organic crystals for pulse shape discrimination. IEEE Trans. Nucl. Sci. 2009, 56, 899-903. [CrossRef]

40. Brubaker, E.; Steele, J. Neutron imaging using the anisotropic response of crystalline organic scintillators. IEEE Nucl. Sci. Symp. Conf. Rec. 2010, 1647-1652. [CrossRef]

41. Zaitseva, N.; Glenn, A.; Carman, L.; Paul Martinez, H.; Hatarik, R.; Klapper, H.; Payne, S. Scintillation properties of solution-grown trans-stilbene single crystals. Nucl. Inst. Methods Phys. Res. Sec. A Accel. Spectrom. Detec. Assoc. Equip. 2015, 789, 8-15. [CrossRef]

42. Cieślak, M.J.; Gamage, K.A.; Glover, R. Pulse shape discrimination characteristics of stilbene crystal, pure and ${ }^{6} \mathrm{Li}$ loaded plastic scintillators for a high resolution coded-aperture neutron imager. J. Instrum. 2017, 12, P07023. [CrossRef]

43. Inrad Optics. Stilbene Single Crystals Data Sheet. 2019. Available online: https://www.inradoptics.com/pdfs / datasheets/InradOptics_Datasheet_Stilbene_Final.pdf (accessed on 11 September 2019).

44. Becchetti, F.D.; Torres-Isea, R.O.; Di Fulvio, A.; Pozzi, S.A.; Nattress, J.; Jovanovic, I.; Febbraro, M.; Zaitseva, N.; Carman, L. Deuterated stilbene (stilbene-d12): An improved detector for fast neutrons. Nucl. Inst. Methods Phys. Res. Sec. A Accel. Spectrom. Detec. Assoc. Equip. 2018, 908, 376-382. [CrossRef]

45. Carman, L.; Paul Martinez, H.; Voss, L.; Hunter, S.; Beck, P.; Zaitseva, N.; Payne, S.A.; Irkhin, P.; Choi, H.H.; Podzorov, V. Solution-Grown Rubrene Crystals as Radiation Detecting Devices. IEEE Trans. Nucl. Sci. 2017, 64, 781-788. [CrossRef]

46. Van Eijk, C.W. Fast Lanthanide-Doped Inorganic Scintillators. In Proc. SPIE 2706, Tenth Feofilov Symposium on Spectroscopy of Crystals Activated by Rare-Earth and Transitional-Metal Ions; SPIE: Bellingham, WA, USA, 1996; Volume 2706. [CrossRef]

47. Reeder, P.L.; Bowyer, S.M. Calibration of LiBaF 3: Ce scintillator for fission spectrum. Nucl. Inst. Methods Phys. Res. Sec. A Accel. Spectrom. Detec. Assoc. Equip. 2002, 484, 469-485. [CrossRef]

48. Kamada, K.; Yanagida, T.; Pejchal, J.; Nikl, M.; Endo, T.; Tsutsumi, K.; Fujimoto, Y.; Fukabori, A.; Yoshikawa, A. Crystal Growth and Scintillation Properties of Ce Single Crystals. J. Cryst. Growth 2012, 59, 2112-2115. [CrossRef]

49. Singh, A.K.; Tyagi, M.; Singh, S.G.; Desai, D.G.; Tiwari, B. Development of Ce doped $\operatorname{Li}_{6} \mathrm{Y}_{(\mathrm{BO}} \mathrm{B}_{3} \mathrm{Crystal}$ Based Portable Solid State Detectors for Thermal Neutrons. BARC Technology Development Article. Bhabha Atomic Research Centre (BARC), 2015; pp. 20-24. Available online: https:/ / pdfs.semanticscholar.org/3fee/ 3c8cc20afe4afbbbb728f6a6c842daabcf0f.pdf?_ga=2.14556031.995535344.1568162717-243878714.1565515068 (accessed on 11 September 2019). 
50. Yanagida, T.; Yamaji, A.; Kawaguchi, N.; Fujimoto, Y.; Fukuda, K.; Kurosawa, S.; Yamazaki, A.; Watanabe, K.; Futami, Y.; Yokota, Y.; et al. Europium and Sodium Codoped $\mathrm{LiCaAlF}_{6}$ Scintillator for Neutron Detection. Appl. Phys. Express 2011, 4, 106401. [CrossRef]

51. Weber, M.J. Inorganic scintillators: Today and tomorrow. J. Lumin. 2002, 100, 35-45. [CrossRef]

52. Shiran, N.V.; Gektin, A.V.; Neicheva, S.V.; Kornienko, V.A. Optical and scintillation properties of LiCaAlF 6 : Eu crystal. J. Lumin. 2003, 103, 815-818. [CrossRef]

53. Melcher, C.L.Ã. Perspectives on the future development of new scintillators. Nucl. Inst. Methods Phys. Res. Sec. A Accel. Spectrom. Detec. Assoc. Equip. 2005, 537, 6-14. [CrossRef]

54. Mukhopadhyay, S.; Mchugh, H.R. Portable gamma and thermal neutron detector using ${ }^{6} \mathrm{LiI}(\mathrm{Eu}) \mathrm{crystals}$. In Proc. SPIE 5198, Hard X-Ray and Gamma-Ray Detector Physics V; International Society for Optics and Photonics: Bellingham, WA, USA, 2004; Volume 5198, pp. 73-82.

55. Nikl, M.; Yoshikawa, A. Recent R\&D Trends in Inorganic Single-Crystal Scintillator Materials for Radiation Detection. Adv. Opt. Mater. 2015, 3, 463-481. [CrossRef]

56. Yoneyama, M.; Kataoka, J.; Arimoto, M.; Masuda, T.; Yoshino, M.; Kamada, K.; Yoshikawa, A.; Sato, H.; Usuki, Y. Evaluation of GAGG:Ce scintillators for future space applications. J. Instrum. 2018, 13, P02023. [CrossRef]

57. Eljen Technology. Neutron/Gamma PSD Liquid Scintillator EJ-301, EJ-309 Data Sheet, Eljen Technology, 2018. Available online: https://eljentechnology.com/images/products/data_sheets/EJ-301_EJ-309.pdf (accessed on 11 September 2019).

58. Eljen Technology. PSD Plastic Scintillator EJ-276, EJ-276G; Eljen Technology, 2017. Available online: https:/ / eljentechnology.com/images/products/data_sheets/EJ-276.pdf (accessed on 11 September 2019).

59. Zaitseva, N.; Glenn, A.; Paul Martinez, H.; Carman, L.; Pawełczak, I.; Faust, M.; Payne, S. Pulse shape discrimination with lithium-containing organic scintillators. Nucl. Inst. Methods Phys. Res. Sec. A Accel. Spectrom. Detec. Assoc. Equip. 2013, 729, 747-754. [CrossRef]

60. Winyard, R.; Lutkin, J.; McBeth, G. Pulse shape discrimination in inorganic and organic scintillators. I. Nucl. Instrum. Methods 1971, 95, 141-153. [CrossRef]

61. Hunter, J.D. Matplotlib: A 2D Graphics Environment. Comput. Sci. Eng. 2007, 9, 90-95. [CrossRef] 